\title{
Introduction
}

\section{Complexity Theory: A New Way to Think}

Diane Larsen-Freeman

University of Michigan

It was pure good fortune that I encountered Complexity Theory (CT) some years ago. It originates in the physical sciences, and I am a mere dilettante in them. However, from the beginning of my acquaintance with CT, I quickly realized that it had much to offer applied linguists. It challenged my concept of language as a static rule-governed system, maintaining instead that "the act of playing the game has a way of changing the rules" (Gleick 1987, p. 24) ${ }^{1}$, and doing away with the need to posit an innate LAD and preformationism ("the assumption that in order to build a complex structure you need to begin with a detailed plan or template") (Deacon 2012, p. 50).

Besides, I could see how CT had the potential to unite important ontogenetic and phylogenetic processes: Language development, language learning, language evolution, language use, language change. However, it was not only that CT was theoretically satisfying; it also resonated with my personal experience. For one thing, adopting a systems perspective on issues of interest in applied linguistics, rather than a piecemeal approach, made a great deal of sense to me. I had grown somewhat discouraged by common research approaches to second language acquisition (SLA) as I understood them. I found them to be reductionist, atomizing the object of concern and then studying one atom at a time, often through single treatment, pre-testpost-test designs. Controlling for other factors and overly deterministic, it sought to identify the causal factor in SLA, e.g., comprehensible input at an i+1 level. Such approaches too readily dismissed variability as noise or measurement error or attributed it to "outliers." They treated context as a backdrop, removed from the main action. They failed to capture the dynamicity of processes, leading Elman (2003, p. 430) to remark that "This

\footnotetext{
${ }^{1}$ Gleick was not referring to linguistic rules, but rather to rules that govern natural
} phenomena. His observation, however, applies equally well to linguistics, in my opinion. 
tendency to study development as if it were a succession of snap-shots - frozen in time and fixed - is more than odd." For after all, "it's about time..." (p. 430). Then, too, traditional approaches did not account for the nonlinearity of the processes, a nonlinearity that was well-attested in the SLA research literature. In addition, they perpetuated the practice of dichotomizing: form versus meaning (see Larsen-Freeman 2003 for why this is a false dichotomy) or social versus psychological (Larsen-Freeman 2007), for instance, instead of practicing a convergent heuristic, looking for what connects as well as what distinguishes (Morin 2007).

I later came to understand that CT was really a metatheory, still necessitating object theories of language (e.g., usage-based), language development (e.g., emergentism), etc., consistent with its precepts. Nevertheless, as a metatheory, CT has the power to shift paradigms, as Horn's summary indicates (See figure below). CT is also transdisciplinary (LarsenFreeman 2011) in the Hallidayan sense; it avoids the splintering of disciplinary knowledge and creates instead new forms of knowledge, which are thematic, cutting across disciplinary boundaries (Burns 2006). CT has also been widely applied-from business and commerce to organizational development to epidemiology to literature.

\section{Paradigms of Simplicity and Complexity (based on Horn 2008)}

\begin{tabular}{|c|c|}
\hline Paradigm of Simplicity & Para digm of Complexity \\
\hline Adheres to the principle of universality & $\begin{array}{l}\text { Without denying universality, also adopts the } \\
\text { complementary principle that the individual } \\
\text { and the local are intelligible in themselves }\end{array}$ \\
\hline $\begin{array}{l}\text { Seeks to reduce wholes to their simple } \\
\text { constituents }\end{array}$ & $\begin{array}{l}\text { Integrates elements into their ensembles or } \\
\text { complexes }\end{array}$ \\
\hline Seeks principles of order & Looks for self-organization \\
\hline Assumes determinism; linear causality & Looks for relationships \\
\hline $\begin{array}{l}\text { Separates subject from object; observer } \\
\text { from observed }\end{array}$ & $\begin{array}{l}\text { Puts the observer back into the experimental } \\
\text { situation }\end{array}$ \\
\hline Treats contradiction as error & $\begin{array}{l}\text { Regards contradictions as paradoxes...as } \\
\text { indices of a deeper reality }\end{array}$ \\
\hline Thinks monologically & $\begin{array}{l}\text { Thinks dialogically and so relates contrary } \\
\text { concepts in a com plementary manner }\end{array}$ \\
\hline
\end{tabular}

However, I also knew at the time that CT presented a number of problems, especially to researchers. One was how they were to draw boundaries around the object of concern when everything was connected to everything 
else. And, once the boundaries were drawn, an issue was how to undertake the research enterprise in a way that honors the wholeness without becoming awash in holism. New methods would be needed, as would a new lexicon, in order to stimulate innovative thinking and to fundamentally redefine our objects of interest (Larsen-Freeman \& Cameron 2008).

Disappointing to me at first was that there was little uptake by others in the field. However, as with change in complex systems themselves, it seems that the adoption of innovative thinking is uneven, unfolding in fits and starts, not proceeding in a linear fashion. Moreover, I felt that it was important then to get the ideas out - to introduce them to others in the field more widely and to recruit conversation partners. This present volume is a tribute to those partners, and I am grateful to Vera Menezes for proposing and compiling this collection. I am delighted with the work that has been featured here. It is also a demonstration of the robustness of the theory.

As testimony to its robustness, we see evidence in this volume of its applicability to various areas of interest to applied linguists: to vocabulary (Macqueen), to phonology (Mangueira Lima Júnior), to reading (Perales Escudero). We also see its impact in the settings to which it can be applied: not only to the classroom, (Mercer, Perales Escudero, Rosado, Vetromille-Castro), but also virtually: Soares Souza's concept of virtual learning environments as complex adaptive systems, Fidelis Braga's study of the complex dynamics and emergent patterns in on-line learning communities, Paiva Franco's use of narratives with digital natives, and Silva Oyama's "Teletandem" focus on the interaction between two pairs of learners.

In this volume, there are also some new answers to old questions, such as why there is a gap between receptive and productive vocabulary (Caspi \& Lowe). In addition, there is new exploration of a number of concepts central to CT, such as adaptation (Soares Souza), interaction (Fidelis Braga; Vetromille-Castro), variability (Caspi \& Lowie), emergence (Macqueen), recursion (Rosado), scaling (Perales Escudero), and affordances (Soares Souza). Also featured in this volume are methodological innovations in the form of microethnographic lexical trail analysis (Macqueen), design-based research (Perales Escudero), and modeling (Caspi and Lowie), used to simulate patterns of self-organization in complex systems.

I have always perceived there to be an affinity between CT and technology, so it is good to see that technology is well-represented in this volume. In addition to investigating this relationship, there are some 
interesting new applications here, such as evidence for non-linearity present in the mapping of articulatory production and acoustic result in linguistics (Mangueira Lima Júnior). And, there are examples of the novel thinking that CT inspires in "interpretive repertoires" (Perales Escudero), "equifinality" (Soares Souza), and "adaptive imitation" (Macqueen).

An issue that I am wrestling with at the moment is how to acknowledge the uniqueness of the individual learner and yet at the same time relate the uniqueness to more general patterns of behavior and disposition among learners. As Mercer asserts, "the field of learner individual differences has been dominated by a tension which has resonance in complexity perspectives and which is familiar to any teacher; namely, the tension between a focus on the level of the individual and/or on the group as a whole." For this reason, I appreciated Caspi and Lowie's observation that "modeling data on the basis of single cases cannot be generalized to larger populations. However, the inverse limitation holds for cross-sectional studies, which are often not generalizable to individuals." Their observation is an important qualification to any claim in applied linguistics, and one that resonates with those of us who adopt a CT perspective.

I conclude with three thoughts. As I wrote in 1997, I worry that the characteristics of complex dynamic system are applicable to many phenomena. One interpretation of this fact is that a theory that applies to many phenomena is banal. However, another interpretation of its ubiquity is that a theory that applies to many phenomena is profound. Obviously I favor the latter interpretation. Nonetheless, I should state that not everything in this volume coincides with my understanding of CT. That doesn't matter. In keeping with a tenet of CT, I recognize that when new ideas are introduced, there is "a dispersion of control" (Fidelis Braga). However, I do think we have to be careful how we use the terms in CT. For instance, "complex" does not mean "complicated" in CT, nor does "feedback" refer to teacher corrections. I am certainly not claiming to be the ultimate authority when it comes to interpreting the lexicon that CT has given us; I just think we have to be especially careful when we appropriate and apply a theory from another discipline to our own.

Nevertheless, I think we find reasons for optimism in this collection. I agree with Mercer who put it as follows:

Perhaps, as has been my own case so far, the key contribution of complexity perspectives lies in their potential to prompt alternative ways of thinking and open our eyes to different ways of viewing our classrooms. They 
have caused me to question and critically examine my assumptions about aspects of learning and teaching that were unwittingly conceptualized in terms of simplistic, unidirectional, linear patterns and have engendered a greater awareness on my part of the need to be flexible, adaptive, and sensitive to the dynamics in the classroom.

\section{References}

BURNS, A. Applied Linguistics: Thematic pursuits or disciplinary moorings? A conversation between Michael Halliday and Anne Burns. Journal of Applied Linguistics, v. 3, n. 1 p. 113-128, 2006.

DEACON, T. W. Incomplete nature. How mind emerged from matter. New York: W. W. Norton \& Company, 2012.

ELMAN, J. It's about time. Developmental Science, v. 6, n. 4, p 430-433, 2003.

GLEICK. J. Chaos: Making of a new science. New York: Penguin Books, 1987.

HORN, J. Human research and complexity theory. Educational Philosophy and Theory, v. 40, n. 1, p. 130-143, 2008.Horn

LARSEN-FREEMAN, D. Chaos/complexity science and second language acquisition. Applied Linguistics, v. 18, n. 2, p. 141-165, 1997.

LARSEN-FREEMAN, D. Teaching language: From grammar to grammaring. Boston: Cengage, 2003.

LARSEN-FREEMAN, D. Reflecting on the cognitive-social debate in second language acquisition. The Modern Language Journal, v. 91, Focus issue, p. 773787, 2007.

LARSEN-FREEMAN, D. Complex dynamic systems: A new trandisciplinary theme for applied linguistics? Language Teaching, v. 45, n. 2, p. 202-214, 2011. LARSEN-FREEMAN, D. \& CAMERON, L. Complex systems and applied linguistics. Oxford: Oxford University Press, 2008.

MORIN, E. Restricted complexity, general complexity. In C. GERSHENSON, D. AERTS \& B. EDMONDS (Eds.), Worldviews, science and us: Philosophy and complexity. Singapore: World Scientific, 2007, p. 5-29. 